\title{
Медиатранзит темы социального сиротства: исследовательский потенциал
}

Полина Нурилова

В статье представлен инновационный подход к исследованию медиарепрезентаций социальных проблем в СМИ, в рамках которых предполагается создать исследовательский алгоритм на примере освещения социального сиротства с использованием материалов российских массмедиа от 1990 гг. до настоящего времени. Рассмотрена проблема социального сиротства как одна из приоритетных социальных проблем в РФ. Автор анализирует роль СМИ в формировании медиакарьеры и медиатранзита темы социального сиротства.

Ключевые слова: социальное сиротство, СМИ, медиатранзит социальной проблемы.

DOI: 10.30547/mediaalmanah.6.2020.8391
@ Нурилова Полина Витальевна аспирантка кафедры периодической печати факультета журналистики МГУ имени М.В. Ломоносова (г. Москва, Россия), polina.izgilova@yandex.ru

\section{Введение}

Вопрос о том, каким образом сделать освещение в СМИ социальных проблем более эффективным, весьма актуален. В научном плане популярна методика контент-анализа, которая позволяет зафиксировать текущее состояние контента и дать рекомендации по оптимизации медиарепрезентаций проблемы. Мы исходим из предположения о том, что возможны более сложные, но в то же время перспективные подходы кисследованию, которые способны обеспечить не только отражение, но и движение актуальных проблем в сторону их соответствия реальной потребности развития. Настоящая статья показывает возможности такого подхода.

Обратимся к представлению и описанию сущности проблемы. Исторически понятие «сиротство» обозначало категорию детей, у которых умерли родители. Однако в прошлом столетии возникает такое общественное явление, как социальное сиротство. Это понятие означает сиротство при живых родителях. Актуальность изучения вопроса социального сиротства в СМИ выражается растущей потребностью современного общества в комплексном осмыслении данного явления.

В настоящее время социальное сиротство само по себе представляет большую опасность для общества, отрицательным 
образом сказываясь на его состоянии; данное явление сигнализирует о деградации базовых социальных институтов, основным из которых является семья. В России в последнее десятилетие $\mathrm{XX}$ В. произошло резкое увеличение количества детей, оставшихся без попечения родителей. Это объясняется, с одной стороны, произошедшим в результате общественных потрясений 1990 гг. значительным ухудшением качества жизни, приведшим к маргинализации отдельных слоев населения, с другой - развитием системы выявления семей и детей, находящихся в неблагополучных условиях в тот же период. Тем не менее начиная с середины 2000 гг. указанные показатели постепенно сокращаются. Так, если в 2005 г., согласно данным Министерства образования и науки РФ, число детей, оставшихся без попечения родителей, составляло 146405 человек, то в 2009 г. этот показатель сократился до 93806 детей․ К концу 2017 г. было зарегистрировано 50210 детей, а в 2018 г. в РФ были лишены родительских прав родители из 38209 семей. По итогам 2019 г. численность сирот продолжала сокращаться и достигла 43,7 тыс. человек, что на 46\% ниже уровня 2015 г. (87 200 детей-сирот)². Несмотря на обозначившуюся тенденцию к сокращению количества социальных сирот в нашей стране, общий масштаб проблемы требует интенсивного поиска мер по скорейшему ее решению. Характер освещения проблемы в СМИ как раз и является одним из компонентов урегулирования обозначенной проблемы.

В последнее время усиливается роль и влияние СМИ в решении социальных проблем. Они не только активно представляют существующие вопросы детства и сиротства на общественное обозрение, но и участвуют в формировании обыденного сознания, опосредующего поведение современных родителей. Сегодня массмедиа повествуют о социальном сиротстве достаточно много, что не лишает их минусов в отношении освещения проблемы.

\section{Методология}

Методологической основой исследования стали труды социологов, психологов, педагогов по вопросам семьи и детства. Мытакже опирались на официальные статистические данные сборников Федеральной службы государственной статистики, Министерства образования и науки РФ4, Института социально-экономических исследований $\mathrm{PAH}^{5}$. Опираясь на эти труды, мы хотели бы представить исследовательский потенциал использования методологии медиатранзита проблемы, т.е. ее движения и развития в информационном поле страны на протяжении длительного времени. В качестве проверки релевантности данной методологии использовалось пилотное исследование, эмпирическую базу которого составил выборочный контент публикаций в отечественных печатных СМИ и новостных интернет-порталах за период с 1990 по 2019 г.: «Аргументы и факты», «Коммерсантъ», «Независимая газета» и «Российская газета». Эти материалы были подвергнуты анализу и критике, исходя из объема и периодичности информации, содержания публикаций, аргументации, оценок экспертов и комментариев общественности, а также стиля публикаций. Так, методами реализации исследования выступали приемы общего и частного научного познания, включая исторический, социально-политический и психологический анализ вопроса, а также системный анализ проблемы медиатранзита социального сиротства.

Отметим, что несомненная научная новизна пилотного исследования состоит в попытке изучить комплексный анализ влияния СМИ на социальное сиротство в контексте развития проблемы в РФ в наиболее острый для нее период.

\section{Обзор литературы}

Изучению сиротства как социальной проблемы в нашей стране посвящено много работ, проведено большое количество 
разнообразных исследований феномена социального сиротства и его аспектов. Однако тема влияния СМИ на социальное сиротство изучена недостаточно. Как правило, массмедиа являются не объектом, а информационной базой источников исследования.

Теоретическую базу научных изысканий можно условно разделить на две группы: работы отечественных авторов по изучению сиротства как социального явления и труды по проблемам освещения социального сиротства в СМИ. Так, в первую группу входят работы Л.Л. Васильевой (2014), О.И. Дубининой (2015), Г.М. Цинченко (2014), С.А. Герасимовой (2014), И.В. Кирия (2010), И.В. Маркиной (2011), А.Н. Аргемчук ${ }^{6}$. В них вопросы социального сиротства рассматриваются в контексте анализа трансформационных процессов в российском обществе, а также общих проблем детей-сирот. Исследование Г.М. Цинченко (2014) предлагает рассмотреть семью как среду с высочайшим уровнем характеристик для реализации процесса воспитания и социализации детей. Этот институт в российском социуме нуждается в оптимизации за счет приложения комплекса мер и ликвидации кризисной ситуации в семьях, генерирующих социальных сирот. И.В. Маркина (2011) раскрывает суть государственной политики социальной поддержки института семьи, позволяющей предотвратить социальное сиротство.

Вторая группа источников состоит непосредственно из трудов, посвященных проблеме влияния медиа на социальное сиротство: О.А. Андриенко (2014), Ю.В. Морозова (2015), Г.Д. Ушакова, Т.В. Филипенко (2010). В них вопросы социального сиротства рассматриваются в ракурсе достоверности отражения проблемы в СМИ, а также описываются походы и тематика, поднимаемые в массмедиа, дается характеристика конкретных изданий, представлен обзор поднятых проблем, рассмотрены конкретные случаи влияния медиа на проблему социального сиротства. В этих исследованиях, как правило, представлен медиаракурс проблемы на конкретный момент анализа. Рассмотрение ее в долгосрочном периоде не анализировалось. Отдельную группу представляют работы по конструированию социальных проблем в СМИ, исследованию транзита проблем в массмедиа. Эта относительно новая методология разрабатывается исследователями Московского, Казанского, Минского университетов на основе изысканий американских ученых о стадиях развития социальных проблем (Блумер, 2001; Ерофеев (ред.), 2000; Ерофеев (ред.), 2001), введенных в отечественный научный оборот представителями казанской социологической школы (Ясавеев, 2004), а также оригинальными работами российских исследователей, развивших это направление и распространивших его на практику медиа (Елсукова, Купчинова, Рябая, 2010; Сидорская, 2018; Фролова, 2014, 2018). Авторы раскрывают значение и роль решения социальных проблем (например, ВИЧ/СПИД, разнообразные тревожные социальные процессы и тенденции в эволюции нынешнего общества) при помощи медиаинструментов, а также уделяют внимание инновационным методикам решения проблем современного социума на примере публикаций в средствах массовой информации, предлагая версии для ликвидации социальных вопросов с участием прессы как одного из приоритетных средств, способных вывести общество из кризиса.

\section{Социальное сиротство: сущность и состояние проблемы}

Социальное сиротство как массовое социальное явление берет свое начало в 1990 гг. (Дубинина, 2015). В советское время преобладало классическое сиротство, сиротство социальное было явлением исключительным, кроме двух волн массовой беспризорности - в период социально-экономической реформации 1917 г. и по факту 
военных действий в 1941-1945 гг. на густонаселенной территории СССР.

Страна активно устраняла социальное сиротство как негативное явление, формируя из детей, утративших контакты с близкими, полноценных членов общества. Так, в 1920 гг. при ликвидации беспризорности большую роль сыграли как классические интернатные заведения для социальных сирот, так и процесс передачи детей на воспитание в трудовые семьи с выделением государственной поддержки. Проводились массовые акции изъятия детей, ночевавших на улицах, в поездах, вокзалах. А.С. Макаренко достиг вершин педагогического мастерства, работая с бывшими беспризорными детьми, помещенными в колонии для исправления несовершеннолетних преступников.

Новая волна реформ политического, экономического и социального строя России, захватившая страну с 1990 гг., активное воздействие западного мировоззрения и трудовая миграция населения стали причинами очередного раунда социального сиротства. Именно в 1990 гг. произошла ломка «социально-экономического и морально-нравственного здоровья» нации. Трансформация форм семейной организации, распространение сожительства, внебрачной рождаемости, смена семейных ценностных установок в совокупности с растущей безработицей стали катализатором роста численности социальных сирот (Васильева, 2014).

Спецификой сегодняшнего дня для нашего государства является масштаб проблемы и отсутствие четких перспектив ее решения в обозримом будущем. Помимо того, что в последние годы социальное сиротство стало одной из основных проблем детства, это явление отрицательно сказывается на состоянии общества и государства в целом.

Одним из инструментов преодоления социального сиротства является предоставление достоверной информации о детях, оставшихся без попечения родителей. Средства массовой информации, в том числе интернет-СМИ, - важнейший источник и способ формирования общественного мнения. Благодаря их деятельности к решению данной проблемы удается привлекать общественность, правительство, бизнес-структуры и т.д. Феномен социального сиротства был и остается темой для дискуссий в СМИ, однако характер освещения проблемы в массмедиа варьируется в манере повествования, контенте текста, количестве и содержании информации, аргументации.

Сегодня становится ясным, что главная проблема в решении вопросов социального сиротства заключается в том, что вся российская система борьбы с этим негативным явлением достигает поставленных перед ней целей лишь частично: одни проблемы решаются, другие возникают. Задача СМИ отслеживать их и способствовать решению. Так, при рассмотрении экономической составляющей проблемы многие эксперты отмечают, что система российских пособий по беременности и при родах, на детей из бедных и малообеспеченных семей не может рассматриваться как экономический стимул рожать или принимать детей в семью, так как ни одно из этих пособий не обеспечивает даже $25 \%$ среднего дохода домохозяйств, что является нормой для европейских стран. Большинство экспертов согласны с тем, что необходимо увеличить размеры детского пособия и пособия для инвалидов детства, увеличить размер пособия одиноким матерям, по потере кормильца, а также разработать систему экономической поддержки молодых семей.

\section{Понятие медиатранзита и медиакарьеры}

Как известно, успех в решении социальных проблем напрямую связан с изменением поведения людей, чего невозможно добиться без широкого общественного обсуждения этих проблем в медиапространстве. 
Медиаобраз социальной проблемы способен оказать мощное воздействие на ее восприятие и движение, на общественное настроение в отношении к ней (Сидорская, 2018). Оценить эффективность деятельности СМИ в освещении данного явления можно благодаря построению медиакарьеры и медиатранзита социальной проблемы. От того, как пишут о проблемах - мало или много, достоверно или нет, «вширь» или «вглубь», какова динамика медиапокрытия, - зависит и отношение к ним, и вовлеченность широкой аудитории в деятельность по их разрешению. Средства массовой информации способны разбудить внимание аудитории и сделать предметом общественной дискуссии любой проблемный спектр, тем самым обеспечив его движение (Фролова, 2018).

Медиатранзит проблемы в СМИ - это длительный процесс. Так, на первой стадии происходит легитимизация проблемы: признание обществом, оценка ситуации не как частного случая, рокового стечения обстоятельств или чьей-то злой воли, а неизбежного, закономерного итога развития событий. Вторая стадия - проблема становится центром общественных обсуждений, люди ищут пути выхода. Третья - появление официальной реакции на проблему. Четвертая - осуществление и коррекция плана действий по решению проблемы. Такова нормативная модель медиатранзита, от успеха (или неудачи) которого во многом зависит эффективность решений проблемы

Медиакарьера социальной проблемы это своего рода итог медиатранзита, ее жизненный цикл, отдельные фазы которого свидетельствуют о том, как происходит развитие проблемы в публичном пространстве, как она осознается и решается обществом и властными структурами (Фролова, 2018). Момент истины состоит в том, что каждой стадии развития проблемы должны соответствовать определенные журналистские практики. Индикаторами движения могут быть информационные поводы, номенклатуры тематик, характер медийных посланий, жанровые решения, присутствие в текстах тех или иных акторов. Анализ этих индикаторов методами традиционного контент-анализа дает возможность в той или иной мере судить о потенциальной эффективности медиарепрезентаций в движении.

Краткий обзор публикаций подтверждает перспективность такого отражения проблемы в СМИ. Напомним, проблема в 1990 гг. начинает обостряться, но ее освещение в СМИ в данный период ограничивается незначительным количеством текстов (как пример, можно привести публикацию «Детский дом "Альфа" был школой убийц»7). При этом проблема социального сиротства подавалась преимущественно в русле определенной «общественной мифологии», плавно перетекающей от обильного выжимания слезы по поводу «бедных сироток» к живописанию «ужасов казенных домов». Сиротская тематика в СМИ ограничена этими крайностями, причины социального сиротства практически не затронуты. Повествование отличается обилием эмоционально-психологического контента с отсутствием четкой аргументации и подтвержденных данных.

Репортажам о детях-сиротах в 1990 гг. редко удавалось шагнуть за пределы этого подхода «жалко - ужасно». «Жалость» $\mathrm{k}$ детям, оставшимся без попечения родителей по причине маргинализации последних, становится еще одним «краеугольным камнем» тематических материалов. (к «жалости", в частности, сводится значительная часть репортажей из детских домов). Проблема «последствий» тех или иных эмоциональных посылов - это отдельная тема. В данном случае хочется сделать акцент на том, что подача темы детей-сирот в жестких рамках "от ужасов - к жалости» накладывает серьезные ограничения как на достоверность материала, так и на развитие темы как таковой. 
В первое десятилетие XXI в. вопрос освещения в СМИ проблемы социального сиротства набирает обороты: все чаще выходят статьи, посвященные данной тематике, характер контента значительно меняется. Это видно из заголовков печатных и интернет-СМИ: «От сирот поворот»8, «Новый год для сирот»9, «Сироты, которые не сироты»10, «Сироты на экспорт»11, «Сиротский долг»12. Освещая тему социального сиротства в этот период, СМИ выявляют важные аспекты существования и развития проблемы:

- вторичное социальное сиротство, когда приемные родители оформляют отказ от усыновленных детей, оставленных без попечения биологическими родителями;

- скрытое социальное сиротство, когда родители не лишены родительских прав и проживают совместно с ребенком, но не выполняют своих родительских обязанностей;

-усыновление российских сирот родителями-иностранцами;

- материальное обеспечение социальных сирот.

Помимо проблем в прессе появляются статьи о государственной и общественной помощи детям: материальные выплаты, волонтерские движения, благотворительные фонды и т.д.

Наиболее ярким примером отношения к теме социального сиротства в нашей стране является деятельность отечественных СМИ после вступления в силу так называемого «закона Димы Яковлева». В это время в российских массмедиа наблюдается усиление раскола между проправительственными и оппозиционными СМИ. Наибольшее количество сообщений в печатных и онлайн-СМИ пришлось на 21 и 28 декабря 2012 г., когда законопроект был одобрен Госдумой и подписан Президентом РФ (Андриенко, 2014). Всего выявлено 1532 сообщения по этому поводу в эти дни. Однако интересны не только количество, но и содержание самих сообщений, аргументация оппонентов, в которой отчетливо просматриваются непримиримые в своем противостоянии дискурсы. Так, «Российская газета» писала о законопроекте положительно или нейтрально, не допуская критики в его адрес. Практически все публикации на тему закона написаны в жанрах новости или интервью с представителями Государственной Думы. Изданием, критикующим действия правительства и других органов государственной власти, оказалась «Газета.ру». Еще более агрессивную политику в отношении закона, проводила «Новая газета» (в качестве основного метода влияния на общественность газета использует подключение зарубежных оппозиционных источников).

Сегодня СМИ также большое внимание уделяют проблеме социального сиротства в нашей стране, отражая современные реалии данного явления - от освещения острых вопросов, их предъявления на суд общества в негативном ключе до пропаганды здорового образа жизни, семейных и нравственных ценностей: «Место социальных сирот - только в семьях»13, «Без права на игрушки»14, «Мотив сохранения»15, «Две разные системы»16.

\section{Перспективы исследования}

Проблема социального сиротства в нашей стране (как в научной литературе, так и в СМИ) разработана недостаточно полно и объективно. Перспективы освещения проблемы социального сиротства в массмедиа требуют реализации поставленных в исследовании задач на базе общероссийских СМИ, дающих достоверный срез реальных событий в секторе социального сиротства по регионам страны с соотнесением с социально-экономической и нормативно-правовой ситуацией.

Полагаем, что более объемный и содержательно полный анализ контента за 1999, 2009 и 2019 гг. (итоги десятилетий) позволит проследить медиатранзит проблемы и апробированные инновации ее разрешения. 
Аналитический обзор контента по рубрикам и тематике, использованию жанровых решений, характеру посланий и их целевой аудитории, ключевой аргументации позволит сопоставить характер публикаций со стадиями развития социальной проблемы, каждая из которых требует различных информационных контент-стратегий. Такое исследование даст возможность оценить эффективность решения проблемы социального сиротства на протяжении определенных периодов, соотнося качество контента, его направленность сдинамикой изменений в обществе, по данным Росстата о работе социальных, педагогических уч- реждений, правоохранительных органов по вопросам ликвидации социального сиротства как явления. Предложенная методология анализа позволит сделать вывод о том, насколько эффективна медиарепрезентация проблемы. По итогам исследования будут сформулированы оптимальные способы реализации медийных практик сообразно стадии развития проблемы, на основании которыхдля сферы массмедиа удастся сформировать прикладной чеклист рекомендательного характера. Важно ито, что предпринятое исследование и его итоги можно распространить также на репрезентации других социальных проблем.

\section{Примечания}

${ }^{1}$ Сиротство в России: проблемы и пути их решения. М.: [б. и.], 2011. Режим доступа: http://sirotinka.ru/download/sirotstvo_v_rossii.pdf (дата обращения: 22.01.2020).

2 Министерство просвещения Российской Федерации. Режим доступа: https://edu. gov.ru/press/1186/v-rossii-umenshaetsya-kolichestvo-detey-sirot/ (дата обращения: 22.01.2020).

3 Федеральная служба государственной статистики. Режим доступа: https://www. gks.ru/ (дата обращения: 22.01.2020).

${ }_{4}^{4}$ Сиротство в России: проблемы и пути их решения.

5 Институт социально-экономических исследований РАН. Режим доступа: http:// www.iseiran.ru/ (дата обращения: 12.01.2020).

${ }^{6}$ Аргемчук А.Н. Юные изгои: социальные сироты // Труд. 1997. Дек., 23.

7 Степенин М. Детский дом «Альфа» был школой убийц // Коммерсанть. 1997. Дек., 5. Режим доступа: https://www.kommersant.ru/doc/189069 (дата обращения: 15.02.2020).

8 Качуровская А. От сирот поворот // Коммерсантъ. Власть. 2007. Окт., 8. Режим доступа: https://www.kommersant.ru/doc/811851 (дата обращения: 12.02.2020).

9 Панюшкин В. Новый год для сирот // Коммерсантъ. 2002. Дек., 18. Режим доступа: https://www.kommersant.ru/doc/356330 (дата обращения: 13.02.2020).

10 Пятов Г. Сироты, которые не сироты // Аргументы и факты. 2010. Ноябрь, 30. Режим доступа: https://aif.ru/society/22123 (дата обращения: 12.01.2020).

11 Уколов Р. Сироты на экспорт // Независимая газета. 2006. 2 фев. Режим доступа: http://www.ng.ru/events/2006-02-02/6_siroty.html (дата обращения: 20.02.2020).

12 Рудая О. Сиротский долг // Российская газета. 2008. Март, 18. Режим доступа: https://rg.ru/gazeta/rg/2008/03/18.html (дата обращения: 22.02.2020). 
13 Скрипникова О. Место социальных сирот - только в семьях // Независимая газета. 2013. Окт., 30. Режим доступа: http://www.ng.ru/ngregions/2013-10-30/15_siroty. html (дата обращения: 12.01.2020).

${ }^{14}$ Алленова О. Без права на игрушки // Коммерсантъ. 2017. Сент., 18. Режим доступа: https://www.kommersant.ru/doc/3409185 (дата обращения: 15.02.2020).

15 Георги И. Мотив сохранения // Коммерсантъ. 2017. Март, 30. Режим доступа: https:// www.kommersant.ru/amp/3249983 (дата обращения: 12.01.2020).

16 Потапова К. Две разные системы // Коммерсантъ. 2019. Ноябрь, 22. Режим доступа: https://www.kommersant.ru/doc/4163599 (дата обращения: 12.01.2020).

\section{Библиография}

Андриенко О.А. Роль СМИ в освещении проблем сиротства (на примере освещения российскими СМИ «закона Димы Яковлева») // Вестн. гос. ун-та управления. 2014. № 21. С. 217-223.

Блумер Г. Социальные проблемы как коллективное поведение // Контексты современности - II: хрестоматия. 2-е изд., перераб. и доп. / сост. и ред. С.А. Ерофеев. Казань: Изд-во Казанск. ун-та, 2001. С. 150-159.

Васильева Л.Л. Социально-педагогическая характеристика социального сиротства // Изв. Саратовск. ун-та. Новая серия. Сер.: Акмеология образования. Психология развития. 2014. Т. 3. № 2. С. 181-186.

Герасимова С.А. Роль российского телевидения в формировании дискурса социальной справедливости // Культура и образование. Электрон. науч.-практ. журнал. 2014. № 1 (5). Режим доступа: http://vestnik-rzi.ru/2014/01/1229/ (дата обращения: 28.02.2020).

Дубинина О.И. Социальное сиротство: причины возникновения и пути решения // Человек и образование. 2015. № 2 (43). С. 122-124.

Елсукова Н.А., Купчинова Т.В., Рябая Г.С. Конструирование социальной проблемы в печатных СМИ // Социология. 2010. № 1. С. 119-125.

Кирия И.В. Социальная тематика в СМИ в России в контексте «общественной службы» // Реклама и право. 2010. № 2. С. 30-32.

Контексты современности - I: Актуальные проблемы общества и культуры в западной социальной теории: хрестоматия / сост. и ред. С.А. Ерофеев. 2-е изд., перераб. и доп. Казань: Изд-во Казанск. ун-та, 2000.

Контексты современности - II: хрестоматия. 2-е изд., перераб. и доп. / сост. и ред. С.А. Ерофеев. Казань: Изд-во Казанск. ун-та, 2001.

Маркина И.В. Политика поддержки семьи как стратегия профилактики социального сиротства: дис. ... канд. социол. наук. Саратов, 2011.

Морозова Ю.В. «Социальное сиротство»: подходы СМИ к острой теме // Исследовательская деятельность студентов: научные и прикладные аспекты общественных и гуманитарных дисциплин: сб. науч. ст. М.: Перо, 2015. С. 199-205.

Сидорская И.В. Медиатранзит актуальных социальных проблем: роль PR-сопровождения в их позиционировании и решении // Знак: проблемное поле медиаобразования. 2018. № 2 (28). С. 228-237.

Ушакова Г.Д., Филипенко Т.В. Отражение социальной сферы на страницах центральной прессы в 90-е годы XX - первое десятилетие XXI века // Филологический журнал. 2010. № 1 (17). С. 130-136.

Фролова Т.И. Гуманитарная повестка российских СМИ. Журналистика, человек, общество. М.: МедиаМир, 2014. 
Фролова Т.И. Медиакарьера социальных проблем: к вопросу об инновационных методах исследования СМИ // Социально-гуманитарные знания. 2018. № 8. С. 56-71.

Цинченко Г.М. Социальное сиротство как феномен современного детства // Вестн. С.-Петербургск. ун-та. Сер.: Социология. 2014. № 1. С. 207-213.

Ясавеев И.Г. Конструирование социальных проблем средствами массовой коммуникации. Казань: Изд-во Казанск. ун-та, 2004. 